\title{
THE EFFECTIVENESS OF THE AUDITORY STEADY STATE RESPONSE IN DIAGNOSING HEARING LOSS IN INFANTS
}

\section{De Wet Swanepoel}

M. Communication Pathology

Lecturer, Department of Communication Pathology, University of Pretoria

Corresponding author: dswanepoel@postino.up.ac.za

\section{Dunay Schmulian}

M. Communication Pathology

Lecturer, Department of Communication Pathology, University of Pretoria

\author{
René Hugo \\ D Phil. Communication Pathology \\ Professor, Head of Department of Communication Pathology, University of Pretoria
}

Key words: Evoked response audiometry; auditory steady state response; amplitude modulated tone; crosscheck principle

\author{
Abbreviations \\ ERA - Evoked Response Audiometry \\ AER - Auditory Evoked Response \\ ABR - Auditory Brainstem Response \\ ASSR - Auditory Steady State Response
}

\section{SUMMARY}

This paper aims to provide a review of the emerging Auditory Steady State Response in light of existing procedures for diagnosis of hearing loss in infants. Determining the type, degree, and configuration of hearing loss in infants is a challenge requiring sophisticated electrophysiological equipment of which Auditory Evoked Responses, and more specifically the Auditory Brainstem Response, are currently the most reliable and widely used. These techniques, however, present with definite limitations. An emerging technique, the Auditory Steady State Response, promises to address many of the existing limitations of Auditory Evoked Response techniques. The Auditory Steady State Response exhibits the potential to estimate reasonably accurate frequency specific hearing thresholds across low and high frequencies in a time-efficient manner. Accurate diagnosis of the magnitude and configuration of hearing loss is the first and primary step toward effective and accountable intervention services to hearing impaired infants. The Auditory Steady State Response technique, however, requires further clinical validation and should be used in combination with the Auditory Brainstem Response. This will ensure that results are cross-checked and that more accurate and reliable diagnosis of hearing loss is made.

\section{OPSOMMING}

Hierdie artikel poog om 'n oorsig te verskaf van die opkomende Ouditief Standhoudende Respons teenoor huidige prosedures wat gebruik word om gehoorverlies in babas en jong kinders te diagnoseer. Bepaling van die tipe, graad en konfigurasie van gehoorverlies in babas en jong kinders is 'n uitdaging wat gesofistikeerde elektrofisiologiese apparaat vereis waarvan Ouditief Ontlokte Response, en meer spesifiek die Ouditiewe Breinstam Respons, huidiglik die mees betroubare en algemene prosedure is. Hierdie tegnieke presenteer egter met duidelike beperkings. 'n Opkomende tegniek, die Ouditief Standhoudende Respons, beloof om baie van die huidige 
beperkings van Ouditief Ontlokte Response aan te spreek. Die Ouditief Standhoudende Respons vertoon die potensiaal om akkurate frekwensie spesifieke gehoordrempels oor die lae en hoë frekwensie spektrum te voorspel op 'n tydseffektiewe wyse. Akkurate diagnose van die grootte en konfigurasie van gehoorverlies dien as die eerste en primêre stap na effektiewe en verantwoordbare intervensie dienste vir gehoorgestremde kinders. Die Ouditief Standhoudende Respons benodig egter nog verdere kliniese validasie en behoort in kombinasie met die Ouditiewe Breinstam Respons gebruik te word. Dit sal verseker dat alle resultate geverifieer word en dat meer akkurate en betroubare diagnoses van gehoorverlies gemaak word.

\section{INTRODUCTION}

The acquisition and production of language are perhaps the most important achievements in any child's development. Language opens the door to successful communication and social interaction, it is the code we use to express our feelings, needs, and thoughts and by which we receive and comprehend the feelings, needs, and thoughts of others. This successful mastery is however highly dependent on an adequately functioning auditory system (Northern \& Downs, 2002:127). The development and maturation of the auditory system in a normal-hearing infant follows a standard sequence of behaviours from birth to 12 months. It is the exposure to speech and the experience of sound that shape the auditory system of infants during their first year of life. In actual fact, once a normal-hearing baby is born, it has already been hearing sounds for at least 4 months (Johansson, Wedenberg \& Westin, 1964:188).

The first months of life are critical developmental periods. The fact that hearing-impaired infants miss out on these critical periods of exposure to adequate auditory and language stimulation creates a sense of urgency emphasising the need for early intervention. Although it is only in the last 20 years that early intervention has developed into an internationally accepted means of delivering services to infants and toddlers with special needs, audiologists have been intent on early identification of hearing loss for at least the past 60 years (Northern \& Downs, 2002:259). This commitment to the identification of hearing loss as early as possible was based on the premise that the earlier rehabilitative measures could be implemented, the better the outcomes would be. This sentiment has recently been proven by various research studies, which clearly indicate that infants who are identified with hearing loss soon after birth have an important and measurable advantage over later identified peers (Yoshinaga-Itano,
1995:129; Yoshinaga-Itano \& Apuzzo, 1995:124). This evidence has been so convincing that the Joint Committee on Infant Hearing $(\mathrm{JClH}, 2000)$ produced a statement in 2000 recommending that hearing-impaired infants should be detected within the first few months of life and treatment initiated by the age of 6 months.

Early intervention for children with hearing loss not only stresses the early identification of hearing loss, but also entails the fitting of sound enhancing devices like hearing aids or cochlear implants, the implementation of support and counselling services to caregivers, as well as the provision of aural rehabilitative services (Northern \& Downs, 2002:150). These services, however, are primarily dependant on the detection of hearing loss followed by an accurate diagnosis of the type, degree, and configuration of hearing loss for both ears (Gorga, 1999:29). In other words: successful determination of hearing ability is the basis of all early intervention programs for children with hearing loss.

Evaluating the hearing ability of an infant has always been a challenge to the audiologist. The fact that infants are unable to provide reliable behavioural responses to sound renders conventional audiometric procedures insufficient. Infants are considered a difficult-to-test population requiring specialised means of ascertaining information regarding their hearing abilities. The development of these techniques evolved from early unreliable behavioural observation techniques using 'low-tech' sounds such as clapping hands and ringing keys, to today's sophisticated electrophysiological technologies (Northern \& Downs, 2002:160). Current electrophysiological audiometric procedures aim to provide an objective assessment of auditory sensitivity at different frequencies for difficult-to-test populations (Gorga, 1999:30)

An accurate evaluation of hearing ability serves as the first step in habilitation, being vital to appropriate inter- 
vention service delivery (Stach, 1998:158). Information regarding the magnitude and configuration of hearing-loss is essential to appropriate amplification of the auditory signal implying that hearing thresholds must be obtained across the audiometric range of frequencies (Gorga, 1999:30). Without this information no amplification, and therefore very limited habilitation, can be done. Initiation of an inappropriate habilitation program due to a lack of knowledge regarding an infant's hearing-loss not only deprives them of critical language acquisition periods, but could even have harmful effects (Gorga, 1999:30).

\section{PROBLEM STATEMENT AND OBJECTIVE}

Against the depicted framework it becomes clear that it is currently a major responsibility in the field of hearing health care to accurately identify frequency-specific hearing thresholds for persons with hearing-loss, especially in the first critical six months of age. This paper, therefore, aims to critically evaluate the possible contribution of an emerging audiometric procedure, the Auditory Steady State Response, in light of existing objective audiometric test procedures.

\section{EVOKED RESPONSE AUDIOMETRY}

The last three decades have seen the development of many electrophysiological measurements, which have been adapted for audiometric purposes in an attempt to provide an accurate objective prediction of hearing thresholds (Rance, Dowell, Rickards, Beer \& Clarck, 1998:48). These procedures have included acousticimmitance measures, otoacoustic emissions, and auditory evoked responses. Although acoustic-immitance and otoacoustic emission measures have proven to be useful screening devices providing valuable information about the integrity of the peripheral auditory mechanism, they do not provide a direct measure of threshold sensitivity (Roeser, Valente \& Hoshford-Dunn, 2000:15; Hall, 2000:25).

Evoked response audiometry (ERA) remains the most useful and effective electrophysiological evaluation of the auditory system (Rance et al. 1998:48). Auditory evoked responses (AERs) are combined electrical potentials representing the neural activity in response to auditory stimuli from the eighth cranial nerve to the cortex (Chiappa, 1990:239). AERs have provided an invaluable audiological avenue into the neural activity of the hearing process, and as more knowledge is being made available in this area it is clear that $A E R s$ will become an even more prominent diagnostic tool in the future of Audiology (Roeser, Valente \& Hoshford-Dunn, 2000:15).

Various AER techniques have been used to predict auditory sensitivity for infants. Most of these techniques, however, have not received widespread clinical appeal because the responses are often dependent on state of consciousness and maturation of the nervous system. The auditory brainstem response (ABR), however, has gained clinical appeal dominating the field of objective electrophysiological audiometry for the past three decades (Arnold, 2000:451). This is attributed to the fact that the ABR is unaffected by sleep or sedation and can be detected in all age populations near the behavioural hearing threshold (Chiappa, 1990:246).

The ABR represents the electrical activity generated by the eighth cranial nerve and neural centres and tracts within the brainstem that is responsive to auditory stimulation (Chiappa, 1990:246). It is a transient response elicited by brief acoustic stimuli such as broadband clicks or more frequency-specific stimuli such as tonebursts. A stimulus with an abrupt onset stimulates a large number of neural fibres to respond in synchrony across a range of frequencies. Thus the more abrupt the stimulus the more clearly defined the ABR will be (Hood, 1998:31). The acoustic principle underlying this phenomenon pertains to the relationship between the duration of a stimulus and its frequency content. There is a trade-off between frequencyspecificity and neural synchrony. The more abrupt the acoustic onset of a stimulus, the more frequencies that stimulus contains (Hood, 1998:55). Stimulating a broad region of the cochlear partition all at once will activate a large number of neurons simultaneously, resulting in a synchronous neural discharge. The more synchronous the neural discharge, the better the resulting ABR, but the poorer the frequency-specificity. The longer the duration of a stimulus, the more frequency-specific the stimulus will be (Hood, 1998:96-97).

The ideal and most commonly used stimulus for eliciting the ABR is a broadband click. This is due to the rapid onset of the click and its broad frequency spectral content that results in the activation of a wide area 
of the basilar membrane (Gorga, 1999:31). Since, however, a broad range of frequencies is stimulated, information about hearing sensitivity at specific frequencies cannot be obtained (Oates \& Stapells, 1998:62). On average, the correlation between click $A B R$ and the frequency region of the cochlea is best between 2 - 4kHz (Gorga, 1999:31; Hood, 1998:96), although this may not be true for individual cases (Oates \& Stapells, 1998:63). Therefore the click ABR provides a general assessment of high frequency hearing but does not assess thresholds at different frequencies (Lins, Picton, Picton, Champagne \& Dirieux-Smith, 1995:3051). This poor frequency-specificity of the ABR using click stimuli is an important limitation in the light of rehabilitative measures based on such results. According to Gorga (1999:30) no accountable amplification can or should be fitted on click $A B R$ results alone.

A variety of stimuli and recording methods in combination with $A B R$ measurements have been developed and proposed to provide information for narrower more precise frequency regions (Gorga, 1999:29; Hood, 1998:98). These alternative stimuli and methods include tone bursts and filtered clicks produced with various types of noise and masking techniques. Each type of stimulus has proven advantageous in the estimation of more frequency-specific thresholds but its use has not been without limitations. The selection of the stimulus to be used appears to be dependent upon the desired frequency-specificity, the type of response being recorded, the available amount of time, and availability of equipment (Hood, 1998:98). Most of these methods are time consuming, technologically complex, and requires a trained professional to interpret results (Lins, et al. 1995:3051). This could possibly explain why these methods have not been introduced into clinical practice on a large scale (Gorga, 1999:41).

Two additional limitations of the Auditory Brainstem Response are firstly, that the interpretation of results is subjective. Although the ABR do not require subjective responses from the subject being tested, determining whether a response is present or not requires subjective interpretation by a trained professional (Lins, et al. 1995:3051). Secondly, the maximum presentation level of both click and tone burst ABR stimuli is limited. The possibility of residual hearing at profound levels, therefore, cannot be investigated thoroughly (Rance, et al. 1998:48).
In light of the importance for accurate assessment of hearing ability for rehabilitative purposes, and the limited clinical test time available to perform such a procedure for infants (Bachmann \& Hall, 1998:43), the ABR's limitations must be taken into consideration. There is a need for an objective audiometric technique that addresses the limitations of the ABR being able to provide an accurate estimate of hearing thresholds across the frequency range in a time-efficient manner.

\section{THE AUDITORY STEADY STATE RE- SPONSE}

Recently a new addition to the field of objective audiometry has indicated the promise of providing a valuable contribution to the currently used test-battery of AERs. The auditory steady state response (ASSR) demonstrates unique characteristics to address many of the limitations presented by the most widely used AER, the ABR (Hood, 1998:117). These responses are commonly referred to as steady state responses (SSRs) or steady state evoked responses (SSEPs) representing the synchronous discharge of auditory neurons in the brainstem stimulated by amplitudemodulated tones (Perez-Abalo, Savio, Torres, Martin, Rodriguez \& Galan, 2001:201). Unlike ABRs obtained with brief transient stimuli, ASSRs are evoked using sustained continuous tones that produce evoked responses occurring during the time-varying stimulus rather than occurring after an abrupt onset of a stimulus. The modulated tones consist of a carrier frequency (test frequency) modulated by a modulation frequency and are as frequency-specific as pure tones (Hood, 1998:117).

The principle underlying the ASSR is based on the following cochlear mechanics as outlined by Lins, Picton, Boucher, Durieux-Smith, Champagne, Moran, Perez-Abalo, Martin and Savio (1996:84): Sound waves cause polarisation and depolarisation of the inner hair cells of the cochlea. Only the depolarisation of inner hair cells causes auditory nerve fibres to transmit action potentials. The electrical action potential output of the cochlea therefore contains a rectified version of the acoustic stimuli. This rectification causes the output of the cochlea to have a spectral component at the frequency at which the carrier was modulated. This component, not present in the spectrum of the stimuli, can be used to assess the response of the 
cochlea to the frequency of the carrier tone.

The ASSR stimulus consists of a carrier frequency (test frequency) modulated over time in the amplitude domain at a frequency of modulation (Perez-Abalo, et al.
2001:201). The stimulus is produced by modulating the amplitude of a carrier sine wave with another sine wave, the frequency of modulation (Lins \& Picton, 1995:422). Figure 1 demonstrates the modulation of a pure tone.

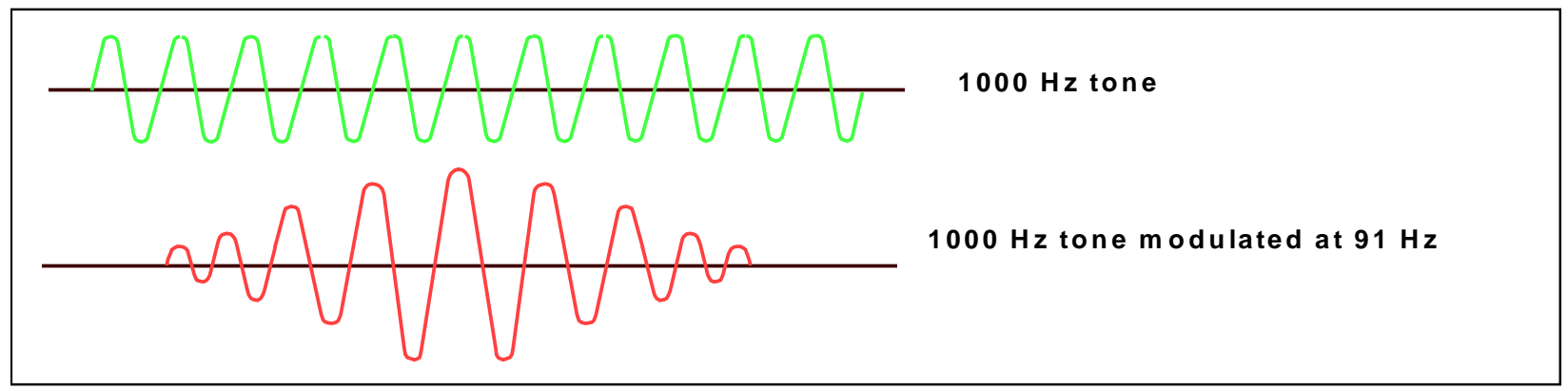

Figure 1: A single tone and a modulated tone

The best modulation rate for audiometric purposes appears to be between $75-110 \mathrm{~Hz}$. This could be because these responses may present the steady state versions of the transient $A B R$ and are therefore not significantly affected by sleep or sedation (Rickards, Tan, Cohen, Wilson, Drew \& Clark, 1994:327). The carrier sine wave is the frequency being tested and can be presented at any low or high frequency tone as in pure tone testing. These modulated tones are therefore very frequency-specific because spectral energy is contained only at the frequency of the carrier tone, and the frequency of modulation (Hood, 1998:118).

The ASSR is generated when the carrier frequency is presented at a rate (the modulation frequency) that is sufficient to cause an overlapping of transient responses, thus being a sustained response. A carrier frequency stimulus vibrates a specific region of the basilar membrane, stimulating a group of hair cells and auditory nerve fibres at this location, at the rate of modulation (Lins, et al. 1996:85). This means that the carrier frequency stimulates the cochlea with pockets of energy at the rate of the modulation frequency. The energy in the resultant response is at the frequency of modulation and its harmonics, allowing analysis of the response in the frequency domain (Herdman \& Stapells, 2001:41). The AER is however recorded in the time-domain and must therefore be converted to the frequency domain by a Fast Fourier Transform (FFT) for analysis. In the frequency domain, the response to the carrier frequency can be assessed by the amplitude and phase of the FFT component corresponding to the frequency of modulation of the carrier. Combining responses whilst maintaining both phase and amplitude information obtain an averaged response (Perez-Abalo, et al. 2001:201). Figure 2 illustrates this procedure.

Responses can be detected using automatic and objective response detection protocols that compare the response to the background EEG activity. Automatic response detection protocols rely on statistical methods to decide whether a response is present or not. These methods basically evaluate whether a response at the frequency of stimulation (modulation) is different from the noise at adjacent frequencies (Lins, et al. 1996:82). By recording responses at descending intensities, a threshold or minimum response level can be obtained at the lowest intensity eliciting a response.

\section{ADVANTAGES OF THE AUDITORY STEADY STATE RESPONSE}

The ASSR evoked responses present definite advantages over transient evoked responses such as the ABR in the prediction of frequency-specific thresholds. 


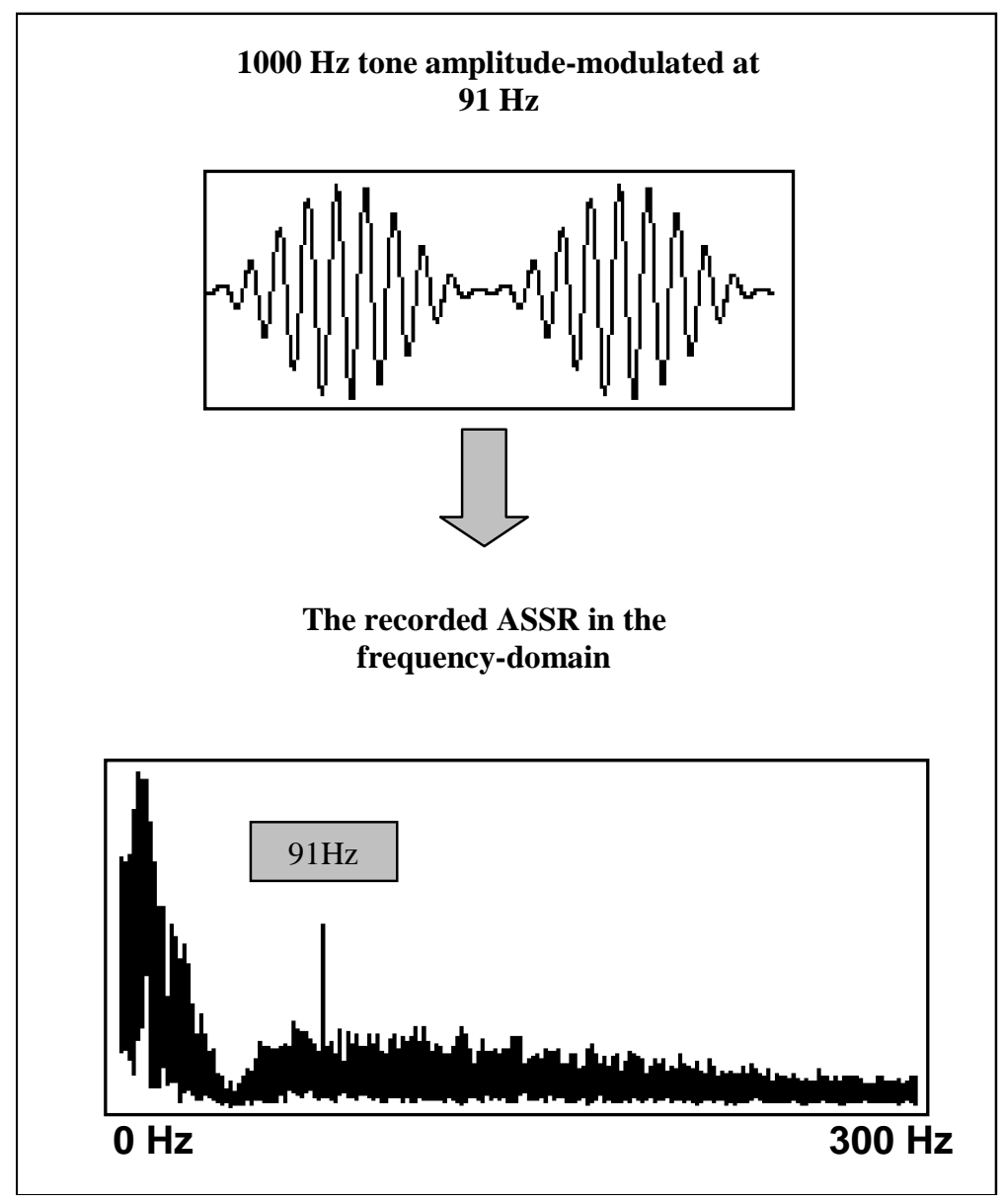

Figure 2: The amplitude-modulated tone stimulates the cochlea in the frequency region of the carrier tone at the rate of the modulation frequency. This produces an AER that is converted from the time-domain to the frequency-domain by a Fast Fourier Transform. The ASSR is subsequently analysed in the frequency-domain by comparing the amplitude of the response at the frequency of modulation to the surrounding frequencies.

\section{Figure 2: Recording the ASSR}

- Auditory Steady State Responses are, first of all, frequency-specific. This can be attributed to the fact that the stimuli used are continuous tones that do not suffer the spectral distortion problems associated with brief tone bursts or clicks (Rance, et al. 1998:49).

- Since the evoked response is periodic, it can best be represented in the frequency domain thereby simplifying measurements. The response can be determined at the frequency of modulation by a computer using well-established statistical procedures, inferring that no subjective judgment by an interpreter is necessary (Lins, et al. 1995:3052).

- Another advantage of the ASSR above transient AERs lies in the continuous nature of the amplitude modulated tones offering a higher presentation level advantage over transient stimuli. This enables a better investigation of ears with minimal amounts of hearing of up to $125 \mathrm{~dB} H \mathrm{HL}$ than the $\mathrm{ABR}$, which presents a maximum presentation level of between 90 - $100 \mathrm{~dB} \mathrm{nHL}$ (Rance, et al. 1998:49).

- Stimuli used to evoke the ASSR can probably provide a better evaluation of hearing aid performance than transient stimuli. Hearing aids and cochlear implants will more readily process steady state stimuli with much less signal distortion because it does not have the abrupt changes over time, which is characteristic of transient stimuli (Lins, et al. 1996:82; Collet, Gallégo, Durrant \& Truy, 2001).

These advantages are very convincing and demonstrate numerous promising applications of the ASSR technique in clinical practice. It must be considered, however, that if each frequency for both ears is explored separately the procedure can still prove to be very time consuming (Perez-Abalo, et al. 2001:201). Evaluat- 
ing each frequency consecutively will require the same amount of time as an evaluation across frequencies with tone burst $A B R s$.

An optimised variant of the ASSR was recently proposed using multiple simultaneous amplitude-modulated tones (Lins \& Picton, 1995:421). This implies that distinct modulation rates, that are more than one octave apart, are used for carrier tones at different frequencies. The modulated tones are added into a complex acoustic stimulus capable of simultaneous activation of different frequency regions within the cochlea. This technique is further optimised if two differently modulated multiple frequency stimuli are presented simultaneously to the left and right ears. In such a case multiple frequencies are explored simultaneously in both ears (Perez-Abalo, et al. 2001:202).

John, Lins, Boucher and Picton (1998:77) reported that ASSR amplitudes to the simultaneous presentation of four steady state tones to one ear were not significantly different from amplitudes when each steady state tone was presented alone, provided the carrier frequencies were at least one octave apart. Herdman and Stapells (2001:46) reported that presenting multiple steady state tones simultaneously to both ears produced thresholds that were the same as single or multiple steady state tones presented to just one ear. These results indicate that there are no significant interactions between multiple stimuli presented simultaneously that have a significant effect on the amplitude of the ASSR. Herdman and colleagues (2001: Personal correspondence) have also demonstrated that the place specificity in the cochlea for both single and multiple ASSRs for normal hearing subjects are good.

It is therefore possible to explore multiple frequencies simultaneously in both ears, significantly decreasing the time needed to evaluate thresholds at multiple audiometric frequencies binaurally. According to Lins et al. (1995:3052) using the MF ASSR for estimating hearing thresholds could be several times more efficient than using an $A B R$ protocol and results could be represented as a conventional audiogram indicating the minimum response level of the ASSR at each frequency.

\section{VALIDATION OF THE AUDITORY STEADY STATE RESPONSE}

The final goal of objective audiometry is to provide accurate hearing thresholds in a frequency-specific manner in order to construct an audiogram without any conscious response from a subject (Aoyagi, Yamazaki, Yokota, Fuse, Suzuki, Itoh \& Watanabe, 1996:7). Since objective audiometry is mostly aimed at the paediatric population, it also requires that the maximum amount of auditory threshold information be acquired in the shortest possible time (Bachmann \& Hall, 1998:42). These requisites for objective audiometry are therefore the primary concern when validating different techniques, including the ASSR. Table 1 summarises reports on how accurate the ASSR estimates behavioural thresholds and on the recording time required. These validations were performed primarily on adult subjects and although response amplitudes are smaller for young infants than those found in adults the ASSR thresholds are within $10 \mathrm{~dB}$ of adult thresholds (Lins, et al. 1996:92). Table 1 on next page.

Reported behavioural threshold estimation results suggest that ASSR thresholds demonstrate some variability being recorded at between 5 to $30 \mathrm{~dB}$ from behavioural thresholds. According to Lins, et al. (1995:3059) these differences may be accounted to possible intersubject variability, different recording time periods, and different statistical response detection techniques used in these studies. Another reason for variations in the threshold differences is because ASSR thresholds for hearing impaired subjects are, on average, closer to behavioural thresholds than for normal hearing subjects (Picton, Durieux-Smith, Champagne, Whittingham, Moran, Giguére \& Beauregard, 1998:326; Perez-Abalo, et al. 2001:208). Authors agree that the smaller difference most probably reflects an abnormal increment in the response amplitude, at above threshold intensities, due to the presence of recruitment. Recording times also present with reasonable variability. This variability is probably due to the use of different averaging periods, recording intensity steps, and acoustical environments.

The ASSR demonstrates the potential to address many of the limitations that current AER techniques exhibit, but as is evident from the variability in current research reports concerning threshold differences and recording times, the technique requires extensive clinical validation. This becomes especially important with the 
Table 1: Reported behavioural and ASSR threshold differences and ASSR recording times

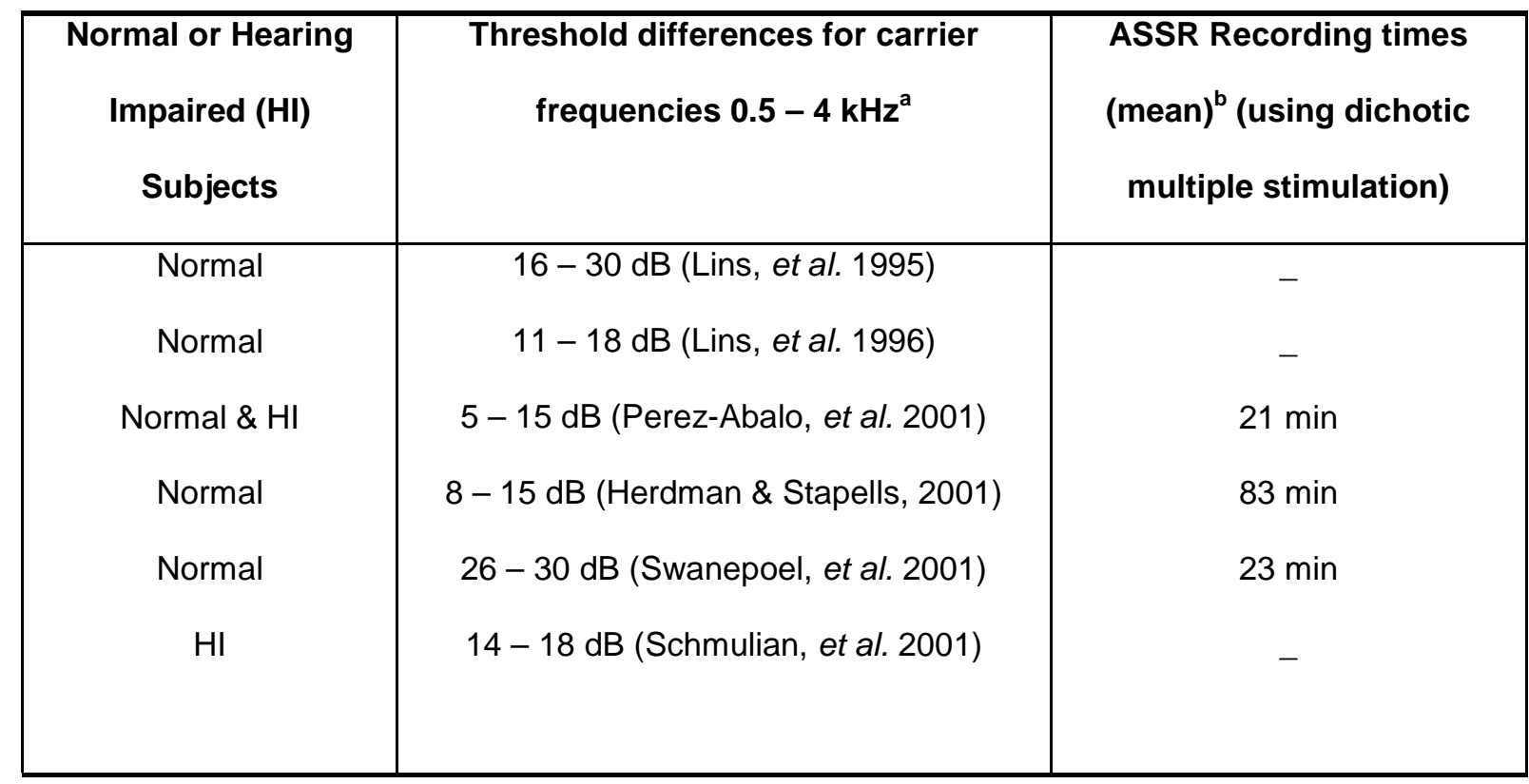

${ }^{a}$ The average difference between behavioural and ASSR thresholds at corresponding frequencies between 0.5 $-4 \mathrm{kHz}$

${ }^{b}$ Reported average recording times for recording thresholds at four frequencies simultaneously in both ears with the dichotic multiple frequency auditory steady state response

first commercial ASSR system having become available in 2001, with other systems following suit in the near future.

\section{FUTURE OF THE AUDITORY STEADY STATE RESPONSE}

In 1991 Picton (1991:9) stated that "Once one has come to the idea that there is more to evoked potential audiometry than the ABR, it may not be hard to accept that there is more to audiometry than clicks and tones". These words are ringing true with the advent of the ASSR evoked with amplitude-modulated tones, promising to establish a new precedent for objective audiometry that will improve early intervention service delivery for hearing impaired infants.

The advent of the ASSR and the potential possibilities thereof is stirring excitement amongst clinicians. Research endeavours are continuously aiming to optimise the ASSR. Recently John, Dimitrijevic, Van Roon and Picton (2001:12) reported that the use of a weighted averaging technique, instead of normal averaging in determining responses, proved more effective espe- cially at lower intensities often requiring less data. Another technique also proposed by these researchers demonstrating potential for better response detection, is the use of mixed modulation (John, et al. 2001:12). This technique involves the modulation of a carrier frequency in the amplitude and frequency domain. Thus, instead of using only amplitude-modulated tones, the tones are now modulated in amplitude and frequency. Initial results indicated that responses evoked by these stimuli are more rapidly detected than those evoked by amplitude-modulated tones only.

A promising new combination of stimuli recently suggested by Stürzebecher, Cebulla and Pschirrer (2001:63), has been reported to increase the amplitude of the ASSR by using multiple carriers. Multiple carriers, differing from each other by plus or minus two times the modulation frequency, are modulated at the same frequency and presented simultaneously to an ear. Although this multiple-carrier stimuli technique implies that the frequency specificity is somewhat lower than single carrier stimuli, it indicates the possibility of providing significant responses close to threshold in shorter periods of time. The technique however requires 
further validation especially for infants (Stürzebecher, Cebulla \& Pschirrer, 2001:67).

According to Picton (2001: Personal communication) the future use of the ASSR will not only be limited to estimating hearing thresholds but promises exciting application abilities for supra-threshold data relating to actual perception as well as monitoring of auditory processing skills.

\section{CONCLUSION}

Procedures and techniques available for evaluation of hearing are increasing with the rapid advancements in technology. This has necessitated the comparative evaluation of the clinical usefulness of these techniques for diagnosing hearing loss in infants. For the assessment of auditory functioning in infants with the ASSR, this implies the implementation of a test-battery approach using the cross-check principle. This states that the results of a single test must be cross-checked by an independent test measure (Hannley, 1986:10). The most important rationale for employing a cross-check principle approach to auditory assessment is the fact that the information provided by an assessment provides the foundation for intervention and rehabilitation. Inappropriate or incomplete diagnostic conclusions will lead to inappropriate management plans and the results can be devastating (Gorga, 1999:29).

Both the ABR and ASSR present with unique characteristics that can and should be incorporated into an objective audiometry test battery to complement, and cross-check results. The click $A B R$ represents a larger more robust neural response than the ASSR and is therefore often able to produce better, more reliable responses at low levels of stimulation. This advantage in the accuracy and reliability of the click ABR is compromised, however, by its lack of frequency-specificity. It therefore seems necessary to combine the ASSR and $A B R$ in a test battery as the techniques are independent measures of auditory sensitivity that are able to provide different, though complementing information. Regan (1989:34) emphasised this fact by stating that transient and steady state recordings are complementary to some extent: each presenting with its own advantages and disadvantages.

It can therefore be recommended that audiologists should:

- take the responsibility for providing accurate and reliable information regarding the auditory sensitivity of a hearing-impaired infant in order to provide effective and accountable intervention services;

- use different techniques to complement each other and to cross-check results. This is the foundation of responsible and effective auditory assessment (Hannley, 1986:11);

- adopt a change of perspective, ensuring that audiometric procedures should not be used in an 'either-or' manner, but rather in the best possible combination providing a more comprehensive set of data regarding hearing threshold from which rehabilitative decisions can be made with more assurance;

- acknowledge and be reminded of the fact that, as the ASSR emerges onto the clinical arena of objective audiometry, it is still but one procedure alongside a battery of tests.

\section{REFERENCES}

AOYAGI, M; YAMAZAKI, Y; YOKOTA, M; FUSE, T; SUZUKI, Y; ITOH, $S$ \& WATANABE, T 1996: Frequency specificity of $80 \mathrm{~Hz}$ amplitude modulation following response. Acta Otolarnygologica, Supplement, 522:6-10.

ARNOLD, SA 2000: The auditory brain stem response. (In: RJ Roeser; M Valente \& H Hosford-Dunn eds. 2000: Audiology Diagnosis. Thieme Medical Publishers: New York, pp. 451-470).

BACHMANN, KR \& HALL III, JW 1998: Pediatric auditory brainstem response assessment: The cross-check principle twenty years later. Seminars in Hearing, 19:41-60.

CHIAPPA, KH 1990: Evoked potentials in clinical medicine. New York: Raven Press.

COLLET, L; GALLÉGO, S; DURRANT, JD \& TRUY, E 2001: Electrically evoked multiple auditory steady-state responses recorded in digisonic cochlear-implanted patients. Oral presentation. International Evoked Response Audiometry Study Group (IERASG). Vancouver, 2001.

GORGA, MP 1999: Predicting auditory sensitivity from auditory brainstem response measurements. Seminars in Hearing, 20:2943.

HALL III, JW 2000: Handbook of otoacoustic emissions. San Diego: Singular Publishing Group.

HANNLEY, M 1986: Basic principles of auditory assessment. San Diego: College-Hill Press.

HERDMAN, AT \& STAPELLS, DR 2001: Thresholds determined 
using monotic and dichotic multiple auditory steady state response technique in normal-hearing subjects. Scandinavian Audiology, $30: 41-49$

HERDMAN, AT; PICTON, TW \& STAPELLS, DR 2001: Place specificity of auditory steady state responses. Poster presentation. International Evoked Response Audiometry Study Group (IERASG), Vancouver, 2001.

HOOD, LJ 1998: Clinical applications of the auditory brainstem response. San Diego: Singular Publishing Group.

JOHANSSON, B; WEDENBERG, E \& WESTIN, B 1964: Measurement of tone response by the human fetus. Acta OtoLaryngologica (Stockholm), 57:188-192.

JOHN, MS; LINS, OG; BOUCHER, BL \& PICTON, TW 1998: Multiple auditory steady-state responses (MASTER): Stimulus and recording parameters. Audiology, 37:59-82.

JOHN, MS; DIMITRIJEVIC, A; VAN ROON, P \& PICTON TW 2001: Multiple auditory steady state responses to AM and FM stimuli.

Audiology \& Neuro-Otology, 6:12-27.

JOINT COMMITTEE ON INFANT HEARING 2000: Year 2000 position statement: Principles and guidelines for early hearing detection and intervention program. Audiology Today, Special Issue, August:7-27.

LINS, OG \& PICTON, TW 1995: Auditory steady-state responses to multiple simultaneous stimuli. Electroencephalography and Clinical Neurophysiology, 96:420-432.

LINS, OG; PICTON, PE; PICTON, TW; CHAMPAGNE, SC \& DURIEUX-SMITH, A 1995: Auditory steady-state responses to tones amplitude-modulated at $80-110 \mathrm{~Hz}$. Journal of the Acoustic Society of America, 97:3051-3063.

LINS, OG; PICTON, TW; BOUCHER, BL; DURIEUX-SMITH, A; CHAMPAGNE, SC; MORAN, LM; PEREZ-ABALO, MC; MARTIN, V \& SAVIO, G 1996: Frequency-specific audiometry using steadystate responses. Ear \& Hearing, 17:81-96.

NORTHERN, JL \& DOWNS, MP 2002: Hearing in children; $5^{\text {th }}$ edition. Baltimore: Lippincott Williams \& Wilkins.

OATES, P \& STAPELLS, DR 1998: Auditory brainstem response estimates of the pure-tone audiogram: current status. Seminars in Hearing, 19:61-85.

PEREZ-ABALO, MC; SAVIO, G; TORRES, A; MARTIN, V; RODRIGUEZ, E \& GALAN, L 2001: Steady state responses to multiple amplitude modulated tones: An optimised method to test frequency specific thresholds in hearing impaired children and normal subjects. Ear \& Hearing, 22:200-211.

PICTON, TW 1991: Clinical usefulness of auditory evoked potentials: A critical evaluation. JSLPA, 15:3-18.

PICTON, TW; DURIEUX-SMITH, A; CHAMPAGNE, $S$; WHITTINGHAM, J; MORAN, L; GIGUÉRE, C \& BEAUREGARD, $Y$ 1998: Objective evaluation of aided thresholds using auditory steady-state responses. Journal of the American Academy of
Audiology, 9:315-331.

PICTON, TW 2001: Current status of auditory steady-state responses: A view from IERASG 2001 presentations. Oral presentation. International Evoked Response Audiometry Study Group (IERASG), Vancouver, 2001.

RANCE, G; DOWELL, RC; RICKARDS, FW; BEER, DE \& CLARK, GM 1998: Steady state evoked potential and behavioral hearing thresholds in a group of children with absent click evoked auditory brainstem response. Ear \& Hearing 19:48-61.

REGAN, D 1989: Human brain electrophysiology: Evoked potentials and evoked magnetic fields in science and medicine. New York: Elsevier Science Publishing Co.

RICKARDS, FW; TAN, LE; COHEN, LT; WILSON, OJ; DREW, JH \& CLARK, GM 1994: Auditory steady state evoked potentials in newborns. British Journal of Audiology, 28:327-337.

ROESER, RJ; VALENTE, M \& HOSFORD-DUNN, H 2000: Diagnostic procedures in the profession of audiology. (In: RJ Roeser; M Valente \& H Hosford-Dunn eds. 2000: Audiology Diagnosis. Thieme Medical Publishers: New York, pp. 1-18).

SCHMULIAN, D; SWANEPOEL, D; HUGO, SR; MONTOYA, A \& PEREZ-ABALO, M 2001: The prediction of hearing thresholds in impaired ears with steady state response evoked potentials compared to pure tone audiometry and auditory brainstem response testing. Oral presentation. International Evoked Response Audiometry Study Group (IERASG), Vancouver, 2001.

STACH, BA 1998: Clinical audiology an introduction. San Diego: Singular Publishing Group.

STÜRZEBECHER, E; CEBULLA, M \& PSCHIRRER, U 2001: Efficient stimuli for recording of the amplitude modulation following response. Audiology 40:63-68.

SWANEPOEL, D; SCHMULIAN, D; HUGO, SR; MONTOYA, A \& PEREZ-ABALO, M 2001: The prediction of hearing thresholds in normal ears with steady state response evoked potentials compared to pure tone audiometry and auditory brainstem response testing. Oral presentation. International Evoked Response Audiometry Study Group (IERASG), Vancouver, 2001.

YOSHINAGA-ITANO, C 1995: Efficacy of early identification and intervention. Seminars in Hearing, 15:128-140.

YOSHINAGA-ITANA, C \& APUZZO, M 1995: Early identification of infants with significant hearing loss and the Minnesota child development inventory (MCDI). Seminars in Hearing, 16:124-135. 